\title{
Effect of water dipping on separation techniques of pomegranate (Punica granatum L.) arils
}

\author{
Monalisa Hota* and D. S. Dahiya \\ INDIA \\ *Corresponding author. E-mail: monalishaht86@gmail.com \\ Received: September 4, 2016; Revised received: January 22, 2017; Accepted: April 14, 2017
}

Department of Horticulture, Choudhary Charan Singh Haryana Agricultural University, Hisar- 125004 (Haryana),

\begin{abstract}
For easy separation of arils, pomegranate fruits were subjected to hot water dipping and normal water dipping treatments. Minimum time of separation as $4.10 \mathrm{~min} / \mathrm{kg}$ of fruit was observed in case of hot water $\left(80 \pm 2^{\circ} \mathrm{C}\right)$ dip for $2 \mathrm{~min}$ which was at par with hot water $\left(80 \pm 2^{\circ} \mathrm{C}\right)$ dip for $1 \mathrm{~min}$ as $4.7 \mathrm{~min} / \mathrm{kg}$. All treatments saved time over the traditional method but only hot water dipping was significant without any significant adverse effect on aril quality in comparison with traditional method except anthocyanin and phenols. Anthocyanin content reduced and phenols content increased in comparison to traditional method.
\end{abstract}

Keywords: Arils, Pomegranate, Separation, Water dipping

\section{INTRODUCTION}

Pomegranate (Punica granatum L.) belongs to the plant family Punicaceae. According to Smith (1979), $P$. granatum has chromosome number $2 n=16$ whereas doubled flower varieties have $2 n=18$. According to De Candolle pomegranate is an ancient fruit which has originated from South-West Asia, probably in Iran and some adjoining countries. Even though native to Iran, it is extensively cultivated in Spain, Morocco, Egypt, Afghanistan and Balauchistan. In India, it is found from Kashmir to Kanyakumari but is cultivated commercially on large scale only in Maharashtra. Small scale plantations are also seen in Gujrat, Rajasthan, Karnataka, Tamil Nadu, Andhra Pradesh, Uttar Pradesh, Punjab and Haryana. In India, it is considered as a crop of the arid and semi-arid regions because it withstands different soil and climatic stresses (Kaulgud, 2001). In India, it is cultivated on a small scale covering an area of 0.13 million ha with production of $1.34 \mathrm{MT}$ and productivity of $10.3 \mathrm{MT} / \mathrm{ha}$ (Saxena and Gandhi, 2014).

The fruit known as balausta ripens towards August to September and are handpicked. Fruits are borne terminally on short spurs from mature shoot. They are non climacteric in nature based on the pattern of $\mathrm{CO}_{2}$ and ethylene production. Pomegranate fruit consists of three parts: the seeds, the juice and the peels which include the husk and interior network membranes. The edible portion (arils-bright red pulp surrounding the individual seed) is about $45-61 \%$ of total fruit weight an consists of about $60-85 \%$ juice and $15-25 \%$ seeds (Lee et., 1974, Al-Maimam et al., 2002, Patil et al,. 2002, Kader, 2006) and $33-40 \%$ peel (Jagtap et al., 1992). Pomegranates are a well-known source of many valuable substances, such as hydrolyzable tannins (punicalagins and punicalins) (Gil et al., 2000), condensed tannins (proanthocyanidins) (Poyrazoglu et al., 2002), anthocyanin (Hernandez et al., 1999), phenolic acids (gallic acid and ellagic acid) (Mousavinejad et al., 2009) and organic acids (Poyrazoglu et al., 2002). All these compounds show high antioxidant activity (Garcia-Alonso et al., 2004) and induce health benefits against cancer, cardiovascular diseases and other diseases (Sun et al., 2002). The removal of arils from pomegranate is a difficult process, since the arils of pomegranate are tightly adhered to each other. Removal of seeds manually results in staining of hands and dress of the workers. Moreover, it is labour consuming. Therefore, it is necessary to standardize different separation techniques for separation of pomegranate aril. Keeping in view the above mentioned points, the study is planned with the following objective;

To standardize the separation techniques of pomegranate arils.

\section{MATERIALS AND METHODS}

Medium sized fruits of pomegranate cv. Wonderful were selected for separation. For each treatment four medium size fruits were taken. Before separation the fruits were subjected to following treatments:

$\mathrm{T}_{1}$ - Traditional method*

$\mathrm{T}_{2}$ - Hot water $\left(80 \pm 2^{\circ} \mathrm{C}\right)$ dip for $1 \mathrm{~min}$ 
$\mathrm{T}_{3}$ - Hot water $\left(80 \pm 2{ }^{\circ} \mathrm{C}\right)$ dip for $2 \mathrm{~min}$

$\mathrm{T}_{4}$ - Water $\left(30 \pm 2^{\circ} \mathrm{C}\right)$ dip for $5 \mathrm{~min}$

$\mathrm{T}_{5}$ - Water $\left(30 \pm 2{ }^{\circ} \mathrm{C}\right)$ dip for $10 \mathrm{~min}$

Note* Separation of arils was done manually without any water dipping.

After the treatments, the seeds were separated manually using a stainless steel knife, giving vertical cut to the fruits and collecting the seeds.

The chemical characteristics of arils after separation was determined as described below. TSS and $\mathrm{pH}$ were determined by using hand refractometer and $\mathrm{pH}$ metre respectively. Titrable acidity and ascorbic acid content were determined by AOAC (2000). Sugars were estimated by using the method of Hulme and Narain (1993). Anthocyanin content was estimated by $\mathrm{pH}$ difference method (kirca et al., 2007). Total phenols were estimated by the method of Swain and Hillis (1959). All the statistical analysis was carried out by using OPSTAT statistical software.

\section{RESULTS AND DISCUSSION}

All the treatments saved time over the traditional method but only hot water dipping were significant. Since the arils were tightly adhered to the outer layer and with the peel, the traditional method was difficult and took maximum time $(8.78 \mathrm{~min} / \mathrm{kg})$ for separation of arils from fruit followed by water $\left(30 \pm 2^{\circ} \mathrm{C}\right)$ dip for 10 $\min$, water $\left(30 \pm 2^{\circ} \mathrm{C}\right)$ dip for $5 \mathrm{~min}$, hot water $\left(80 \pm 2^{\circ} \mathrm{C}\right)$ dip for $1 \mathrm{~min}$, hot water $\left(80 \pm 2^{\circ} \mathrm{C}\right)$ dip for $2 \mathrm{~min}$. Minimum time of separation as $4.10 \mathrm{~min} / \mathrm{kg}$ of fruit was observed in case of hot water $\left(80 \pm 2^{\circ} \mathrm{C}\right)$ dip for $2 \mathrm{~min}$ which was at par with hot water $\left(80 \pm 2^{\circ} \mathrm{C}\right)$ dip for 1 $\mathrm{min}$ as $4.70 \mathrm{~min} / \mathrm{kg}$. A similar result was also reported by Aghajain et al. (2012) and Parashar et al. (2009) in pomegranate treated with hot water for easy aril separation.

There was no significant difference between the treatments for TSS, $\mathrm{pH}$ and ascorbic acid content of the fresh arils. Similar result was found by Palma et al. (2013) in tarocco oranges for soluble solid content of the fruit. Djioua et al. (2009) found similar result for TSS in mangoes. No significant difference between the treatments was found for ascorbic acid content of arils though contradictory results were reported by Aghajain et al. (2012) and Parashar et al. (2009). Aghajain et al. (2012) and Parashar et al. (2009) found that the acidity and ascorbic acid content of the pomegranate aril separated by hot water dip was high.

Acidity was significantly at 5\% level of significance affected by the water dipping. Maximum acidity was found in case of water $\left(30 \pm 2^{\circ} \mathrm{C}\right)$ dip for $10 \mathrm{~min}$ $(1.03 \%)$ followed by water $\left(30 \pm 2^{\circ} \mathrm{C}\right)$ dip for $5 \mathrm{~min}$ $(0.97 \%)$, hot water $\left(80 \pm 2^{\circ} \mathrm{C}\right)$ dip for $2 \min (0.86 \%)$, traditional method $(0.73 \%)$ and minimum in hot water $\left(80 \pm 2^{\circ} \mathrm{C}\right)$ dip for $1 \mathrm{~min}(0.66 \%)$. The highest amount of titrable acidity related to fruits which exposed to cold water dipping treatments. Aghajain et al. (2012) reported similar result. They found that titrable acidity of pomegranate aril separated by hot water dip was less than cold water dip and control method.

The anthocyanin content of arils was significantly affected at 5\% level of significance with different water dipping methods. Maximum anthocyanin content was found in case of water $\left(30 \pm 2^{\circ} \mathrm{C}\right)$ dip for $10 \mathrm{~min}$ followed by water $\left(30 \pm 2^{\circ} \mathrm{C}\right)$ dip for $5 \mathrm{~min}$ and traditional method. Minimum anthocyanin content was recorded in case of hot water dipping. Minimum anthocyanin content may be due to degradation of anthocyanin pigments by hot water dipping of fruits.

Water dipping treatments affect the phenols content significantly at 5\% level of significance. Maximum phenol content was recorded in case of hot water $\left(80 \pm 2^{\circ} \mathrm{C}\right)$ dip for $1 \mathrm{~min}(34.66 \mathrm{mg} / 100 \mathrm{~g})$ which was at par with water $\left(30 \pm 2^{\circ} \mathrm{C}\right)$ dip for $10 \mathrm{~min}(34.16$ $\mathrm{mg} / 100 \mathrm{~g})$, water $\left(30 \pm 2^{\circ} \mathrm{C}\right)$ dip for $5 \mathrm{~min}(33.33$ $\mathrm{mg} / 100 \mathrm{~g})$, hot water $\left(80 \pm 2^{\circ} \mathrm{C}\right)$ dip for $2 \mathrm{~min}(32.83$ $\mathrm{mg} / 100 \mathrm{~g}$ ) and minimum phenol of $26.33 \mathrm{mg} / 100 \mathrm{~g}$ was found in case of traditional method. Palma et al. (2013) found that there was no significant difference between the different water treatments for total phenols in tarocco oranges.

Total sugars, reducing sugars and non reducing sugars of arils were significantly affected at $5 \%$ level of significance by water dipping. Total sugars were highest in case of hot water dipping which was at par with water $\left(30 \pm 2^{\circ} \mathrm{C}\right)$ dip for $5 \mathrm{~min}$ and traditional method.

Table 1. Effect of water dipping on separation of arils of five pomegranate fruits per treatment with 3 replication of pomegranate cv. Wonderful.

\begin{tabular}{lcccc}
\hline Treatments & $\begin{array}{c}\text { Fresh fruit average } \\
\text { weight }(\mathbf{k g})\end{array}$ & $\begin{array}{c}\text { Aril average } \\
\text { weight }(\mathbf{g})\end{array}$ & $\begin{array}{c}\text { Rind average } \\
\text { weight (g) }\end{array}$ & $\begin{array}{c}\text { Separation } \\
\text { time } \\
(\mathbf{m i n} / \mathbf{k g})\end{array}$ \\
\hline Traditional method & 1.17 & 594.33 & 565.00 & 8.78 \\
Hot water $\left(80 \pm 2^{\circ} \mathrm{C}\right)$ dip for $1 \mathrm{~min}$ & 1.34 & 683.33 & 641.00 & 4.70 \\
Hot water $\left(80 \pm 2^{\circ} \mathrm{C}\right)$ dip for $2 \mathrm{~min}$ & 1.28 & 669.33 & 596.00 & 4.10 \\
Water $\left(30 \pm 2^{\circ} \mathrm{C}\right)$ dip for $5 \mathrm{~min}$ & 1.27 & 665.33 & 582.00 & 6.81 \\
Water $\left(30 \pm 2^{\circ} \mathrm{C}\right)$ dip for $10 \mathrm{~min}$ & 1.21 & 635.00 & 544.00 & 7.06 \\
C.D. $(\mathrm{P} \leq 0.05)$ & & & & 2.17 \\
\hline
\end{tabular}


Monalisa Hota and D. S. Dahiya / J. Appl. \& Nat. Sci. 9 (2): 763 - 766 (2017)

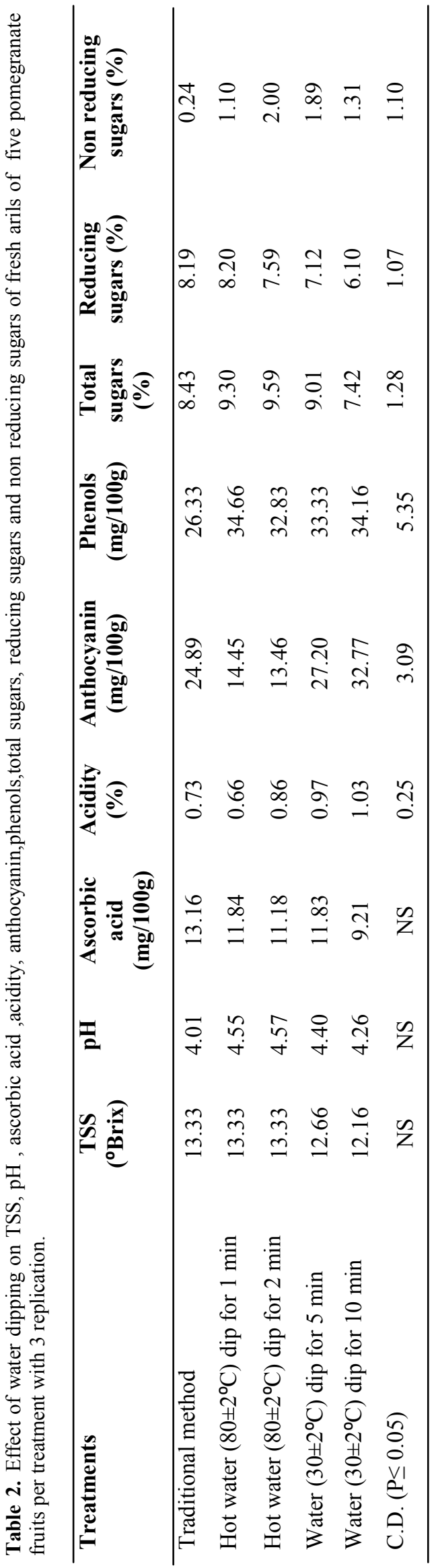

Minimum content of total sugars were reported in case of water $\left(30 \pm 2^{\circ} \mathrm{C}\right)$ dip for $10 \mathrm{~min}$. Reducing sugars were found maximum in case of hot water dipping which was at par with traditional method. Increases of reducing sugar during hot water dip may be due to inversion of sucrose content of arils which produce by heat. A similar observation has been reported by Aghajain et al. (2012)andParashar et al. (2009) for reducing sugars of pomegranate aril treated with hot water dip and Minimum amount of reducing sugars were found in water $\left(30 \pm 2^{\circ} \mathrm{C}\right)$ dip for $10 \mathrm{~min}$. which may be due to entry of water into the fruit. Maximum non reducing sugars were found in hot water $\left(80 \pm 2^{\circ} \mathrm{C}\right)$ dip for $2 \mathrm{~min}$. which was at par with water $\left(30 \pm 2^{\circ} \mathrm{C}\right)$ dip for $5 \mathrm{~min}$., water $\left(30 \pm 2^{\circ} \mathrm{C}\right)$ dip for $10 \mathrm{~min}$., hot water $\left(80 \pm 2^{\circ} \mathrm{C}\right)$ dip for $1 \mathrm{~min}$. and minimum non reducing sugars were recorded in traditional method. The variation in non reducing sugar content of arils may be due to the variation in fruit non reducing sugar that are used for water dipping treatment

\section{ACKNOWLEDGEMENTS}

Choudhary Charan Singh Haryana Agricultural University, Hisar, Haryana, Indiais acknowledged for providing the financial support for conducting this experiment.

\section{REFERENCES}

A.O.A.C., (2000). Official Methods of Analysis. $15^{\text {th }}$ Edn. Association of Official Analytical Chemist, Washington, D.C.

Aghajain, N., Kashiri, M., Garmakhany, A.D., Moharami, M. and Dalvi, M. (2012). Treatments influencing quality attributes and separation time of pomegranate arils. Minerva Biotechnol., 24 (1): 1-4

Al-Maimam, S.A. and Ahmad, D. (2002). Changes in physical and chemical properties during pomegranate (Punica granatum L.) fruit maturation. Food Chem., 76: 437

Djioua, T., Charles, F., Lopez-Lauri, F., Filgueiras, H., Coudret, A., Freire Jr, M., Marie-Noelle, Ducamp-Collin and Sallonon, H. (2009). Improving the storage of minimally processed mangoes (Mangifera indica L.) by hot water treatments. Postharvest Biol. Technol.,52: 221-226

Garcia-Alonso, M., De Pascual-Teresa, S., Santos-Buelga, C. and Rivas-Gonzalo, J.C. (2004). Evaluation of the antioxidant properties of fruits. Food Chem., 84 (1): 1318

Garcia-Alonso, M., De Pascual-Teresa, S., Santos-Buelga, C. and Rivas-Gonzalo, J.C. (2004). Evaluation of the antioxidant properties of fruits. Food Chem., 84 (1): 1318

Gil, M.I., Tomas-Barberan, F.A., Hess-Pierce, B., Holcroft, D.M. and Kader, A.A. (2000). Antioxidant activity of pomegranate juice and its relationship with phenolic composition and processing. J. Agric. Food Chem., 48 (10): 4581-4589

Hernandez, F., Melgarejo, P., Tomas-Barberan, F.A. and Artes, F. (1999). Evolution of juice anthocyanins during 
ripening of new selected pomegranate (Punica granatum) clones. Eur. Food Res. Technol., 210 (1): 39-42

Hulme, A.C. and Narain, R. (1993). The ferrycynide method for determination of reducing sugars. A modification of Hegedom-Jenson Hanes Technique. Biochem. J., 25: 1051-1061

Jagtap, D.B., Desai, U.T. and Kale, P.N. (1992). Chemical composition of some indigenous and exotic cultivars of pomegranate. Maharashtra J. of Hort., 6: 12

Kader, A.A. (2006). Postharvest biology and technology of pomegranates. In: Seeram, N.P., Schullman, R.N. and Heber, D. (Eds) Pomegranates: Ancient Roots to Modern Medicine, Pp: 211-220. CRC Press Taylor and Francis Group, Boca Raton, Florida.

Kaulgud, S.N. (2001). Pomegranate. In: Chadha, K.L. (Eds.), Hand Book of Horticulture, Pp: 397-307. ICAR, New Delhi.

Kirca, A., Ozkan, M. and Cemerglu, B. (2007). Effects of temperature,solid content and $\mathrm{pH}$ on the stability of black carrot anthocyanin. Food Chem., 101: 212-218.

Lee, S.W., Kim, K.S. and Kim, S.D. (1974). Studies on the compositional changes of pomegranate fruit during maturation 1.Changes in sugars, organic acids, amino acids, and the respiration rate. Korean $J$ Horti-c Sci Thechnol, 15: 57

Mousavinejad, G., Emam-Djomeh, Z., Rezaei, K. and Khodaparast, M.H.H. (2009). Identification and quantification of phenolic compounds and their effects on antioxidant activity in pomegranate juices of eight Iranian cultivars. Food Chem., 115 (4): 1274-1278

Palma, A., Aquino, S.D., Vanadia, S., Angionic, A. and Schirra, M. (2013). Cold quarantine responses of 'Tarocco' oranges to short hot water and thiabendazole postharvest dip treatment. Postharvest Biol. Technol., 78: $24-33$

Parashar, A., Gupta, S.K. and Kumar, A. (2009). Studies on separation techniques of pomegranate seeds and their effect on qualityof anardana. Afr. J. Biochem. Res., 3 (10): 340-343

Patil, A.V., Karale, A.R. and Bose, T.K. (2002). Pomegranate. In: Bose, T.K., Mitra, S.K. and Sanyal, D. (Eds) Fruits: Tropical and Subtropical Pp: 125-162. Naya Udyog, Bidhan Sarani. Calcutta. India.

Poyrazoglu, E., Gokmen, V. and Nevzat, A. (2002). Organic acids and phenolic compounds in pomegranates (Punica granatum L.) grown in Turkey. J. Food Comp. Anal., 15 (5): $567-575$

Saxena, M. and Gandhi, C.P. (2014). Indian horticulture database.www.nhb.gov.in

Smith, P.M. (1979). Minor crops. In: Simmonds, N.W. (ed.), Evolution of Crop Plants, Pp: 320. Longman.

Sun, J., Chu, Y.F., Wu, X. and Liu, R.H. (2002). Antioxidant and antiproliferative activities of common fruits. $J$. Agric. Food Chem., 50 (25): 7449-7454

Swain, T. and Hillis, W.E. (1959). The phenolic constituents of Prunus domestica: the quantitative analysis of phenolic constituents. J. Sci. Food Agric., 10: 63-68 